\title{
Letter to the editor concerning "Head to pelvis alignment of adolescent idiopathic scoliosis patients both in and out of brace" by Vergari C, Courtois I, Ebermeyer E, Pietton R, Bouloussa H, Vialle R, Skalli W (Eur Spine J; 2019: https://doi.org/10.1007/ s00586-019-05981-8)
}

\author{
Hans-Rudolf Weiss ${ }^{1}$ (D) Deborah Turnbull ${ }^{2}$
}

Received: 2 June 2019 / Revised: 2 June 2019 / Accepted: 23 June 2019 / Published online: 27 June 2019

(c) Springer-Verlag GmbH Germany, part of Springer Nature 2019

We thank the authors for this very interesting insight into their investigations of the sagittal plane changes in braced patients with adolescent idiopathic scoliosis (AIS). We have a few remarks to make with respect to the content of this study.

- The authors in their article refer to 'the brace' as if there was only one single brace design available. The specific brace used in the study has not been described in any detail; neither has it been documented in a picture, nor did the authors name what kind of brace was used. There are in fact many different brace types currently available on the market. While it is a well-known fact that Boston-style braces reduce lumbar lordosis and increase thoracic flatback, in the recent Chêneau developments (Rigo-Chêneau/Gensingen brace) lumbar lordosis and thoracic kyphosis is implemented. In view of the many different approaches in studies involving braces, (1) the brace should be named, (2) the brace should be shown in at least one picture with a patient in-brace, and (3) the brace should be described in detail including the principles of correction applied, if applicable.

- In figure 8, an X-ray of a patient with kyphoscoliosis is shown with and without a brace apparently demonstrating that the (undefined) brace used reduces thoracic kyphosis and lumbar lordosis as well. The patient shown in this picture, to the trained individual, does not have a typical distortion usually seen in AIS sagittal

Hans-Rudolf Weiss

hr.weiss@skoliose-dr-weiss.com

1 Gesundheitsforum Nahetal, Alzeyer Str. 23, 55457 Gensingen, Germany

2 The London Orthotic Consultancy, 1 Elm Crescent, Kingston upon Thames KT2 6HL, UK alignment (flatback). The pictures shown in figure 8 seem to demonstrate that the brace is flattening the sagittal curvatures both in the thoracic and lumbar regions, which is a negative outcome, seen in typical AIS (flatback) alignments.

- In figure 8, it is also documented that there is no correction of the Cobb angle in the brace. Therefore, the reasons and aims of using such a brace, to improve or even halt scoliosis progression, need to be further clarified. It is well known that in-brace correction of the Cobb angle and compliance (brace wearing time) are the most important parameters to determine treatment success.

In conclusion, the brace along with the in-brace images demonstrates a good correction of a thoracic kyphosis. As the brace flattens the sagittal curvatures of the spine, it does not seem appropriate for the typical AIS patient. Finally, a brace without any correction in the frontal plane as presented in this study, according to the current literature and knowledge, should not be regarded as an appropriate treatment application in the condition of AIS.

\section{Compliance with ethical standards}

Conflict of interest HRW receives financial support for attending symposia and has received royalties from Koob GmbH \& Co KG. The company is held by the spouse of HR Weiss. HRW holds a patent on a sagittal realignment brace (EP 1604624 A1). DT is employed by an orthotic company who provides a variety of orthotics, including spinal bracing.

Publisher's Note Springer Nature remains neutral with regard to jurisdictional claims in published maps and institutional affiliations. 